Boise State University

ScholarWorks

$2-1-2013$

\title{
Osteochondritis Dissecans Development after Bone Contusion of the Knee in the Skeletally Immature: A Case Series
}

Kevin G. Shea

St. Luke's Sports Medicine

John C. Jacobs Jr.

St. Luke's Sports Medicine

Nathan L. Grimm

University of Utah

Ronald P. Pfeiffer

Boise State University 


\title{
Osteochondritis Dissecans Development after Bone Contusion of the Knee in the Skeletally Immature: A Case Series
}

\author{
Kevin G. Shea and John C. Jacobs Jr. \\ St. Luke's Sports Medicine \\ Nathan L. Grimm \\ University of Utah \\ Ronald P. Pfeiffer \\ Boise State University
}

\begin{abstract}
Osteochondritis dissecans (OCD) is thought to be an acquired osteochondral disorder, and its etiology may be multi-factorial. Trauma, both acute and repetitive events, has previously been proposed as a potential cause for OCD development. We present two cases of skeletally immature males who developed a symptomatic OCD lesion following a femoral condyle bone contusion. These cases suggest that an acute traumatic event may lead to the development of OCD of the knee.
\end{abstract}

Keywords: Osteochondritis dissecans, bone contusion, knee, skeletally immature, cartilage injury

\section{Introduction}

Osteochondritis dissecans (OCD) is thought to be an acquired osteochondral disorder, and its etiology may be multifactorial. Fairbank proposed repetitive micro-trauma of the tibial spine onto the lateral aspect of the medial femoral condyle as a potential cause [6]. Trauma, both acute and repetitive events, as well as genetic factors may play a role in the development of this condition [4,7]. Several studies have suggested traumatic incidents as potential causative factors of OCD, although the relationship between higher energy and acute traumatic events is very limited $[3,9,13,19]$.

Two cases are presented of skeletally immature subjects with a history of femoral condyle contusions that were initially identified on MRI sequences after significant knee trauma. In the follow-up period, both patients developed lesions consistent with OCD, suggesting that acute trauma may be one of the causes of OCD lesions.

\section{Case Report}

IRB approval, consent, and assent were obtained for this report. Both patients and their families were informed that these cases were to be submitted for publication, and they gave consent for this.

Case 1. An 11 year-old male was referred to our clinic from the emergency department after he sustained a noncontact, "plant-and-twist" left knee injury playing football, and developed a large effusion. An MRI identified a minimally displaced tibial spine avulsion, and an acute bone contusion on the lateral femoral condyle (Fig. 1). Recent research on tibial spine fractures/avulsion injury has demonstrated a pattern of bone contusions similar to those seen with ACL tears $[17,18]$. The patient was treated with a cast for one month, and returned to regular activity within 3 months of the injury.

Approximately two years after this injury the patient returned to our clinic with pain under his patella and over the lateral aspect of his knee. The patient had no mechanism of injury to explain his onset of symptoms but had been active in sports. This pain had existed for approximately four months prior to his office visit and had limited him 
significantly during exercise. He did not recall any recent trauma, and his symptoms developed spontaneously. Radiographs at this time were normal. An MRI of the knee revealed evidence of a small OCD lesion on his lateral femoral condyle, in a similar location to the acute contusion seen on the previous MRI (Fig. 1). The patient was restricted from playing sports for three months and was advised to limit activity.

At 3-month follow-up, AP and lateral radiographs and an MRI were taken. MRI showed complete resolution of the OCD lesion, with the articular cartilage intact. This resolution was approximately 2.25 years after the initial injury. The patient was released to a gradual return to sports without any restriction. At 2 years of follow-up, he remains asymptomatic.

Case 2. A 15-year-old hockey athlete sustained a right knee injury during a knee-to-knee collision with another player. Because of ongoing symptoms, he was evaluated with an MRI obtained several weeks after the injury. MRI identified a bone contusion of the medial femoral condyle (Fig. 2). A rehabilitation program was recommended and activity was continued without restriction.

Approximately 7 months later, the subject was still having significant pain and catching in this region accompanied by occasional difficulty in full leg extension. A secondary MRI was obtained, and a significant focal cartilage lesion was identified on the medial femoral condyle (Fig. 2). He was treated with subchondral bone drilling. At one-year follow-up, the subject's pain was completely resolved, and the radiographs were normal.

\section{Discussion}

The most important finding of the present study was the possible correlation between femoral condyle bone contusion and osteochondritis dissecans development. Although the etiology of OCD has not fully been elucidated, it is commonly accepted that repetitive micro-trauma may play a significant role in the development of this disorder [3-7,12,21]. One hypothesis for a traumatic incident causing an OCD involves the tibial eminence causing a direct contusion on the medial femoral condyle [6]. Some have proposed repetitive trauma as a cause of OCD of they knee $[3,6,21]$. Fairbank suggested that repetitive trauma of the tibial spine against the femoral condyle can lead to OCD of the medical femoral condyle [6]. However, some have rejected this hypothesis due to its inability to account for OCD development in different joints and other locations in the knee $[9,10]$.

In addition to repetitive micro-trauma, single, significant traumatic events may also play a role in the development of OCD. Krappel proposed a progression from a capitellar bone bruise to an OCD lesion of the elbow [13]. The two cases in this series suggest that a single traumatic event in the knee may lead to delayed development of a type of OCD lesion.

OCD lesions in juveniles have been shown to heal without surgical intervention $[11,16,22]$. However, recent reports have shown that those with stable or low-grade juvenile OCD lesions that do not heal with non-operative measures, may be treated successfully with subchondral bone drilling $[23,2,1]$.

A recent MRI study showed that the largest proportion of bone contusions associated with tibial eminence fractures were associated with the lateral femoral condyle (80\%), although subchondral bone contusions were seen frequently in other areas of the knee as well [17]. This study and others demonstrated that bone contusions are frequently found in skeletally immature patients with a history of a knee injury and associated effusion $[8,14,15,17,20]$.

In these 2 knee injury cases, a single traumatic event may have produced contusions to the lateral femoral condyle. Both patients reported delayed-onset secondary symptoms after the condyle contusions, and the MRI demonstrated the appearance of lesion of the subchondral bone consistent with the development of OCD lesions. The etiology and progression of OCD is still unclear, and repetitive micro-trauma may still play a predominant role in the development of OCD. But, these cases with acute knee injury and evidence of an acute condyle injury in the region that subsequently developed an OCD, suggests that acute traumatic contusions may be another process that leads to the development of OCD. Future studies should be conducted to determine the relationship between subchondral bone contusions and OCD. These future studies could include a study that follows a large number of patients with femoral condyle bone contusions, prospectively, to assess if OCD lesions develop. 
Although the etiology of OCD may still be multi-factorial, suggested etiologic factors have essentially been divided into several categories, including: trauma, vascular, and hereditary [3,4,6,21]. Inflammatory and vascular theories have fallen out of favor, as histopathology studies have not shown consistent signs of either inflammation or largescale ischemia. Repetitive micro-trauma has received more attention in recent years as a primary cause of OCD [12]. In addition to repetitive micro-trauma, acute higher energy impact injuries may also be associated with the development of OCD. These cases suggest that an acute traumatic event may lead to the development of OCD of the knee.

\section{Conflict of Interest}

The authors declare that they have no conflict of interest. 


\section{References}

1. Adachi N, Deie M, Nakamae A, Ishikawa M, Motoyama M, Ochi M (2009) Functional and radiographic outcome of stable juvenile osteochondritis dissecans of the knee treated with retroarticular drilling without bone grafting. Arthroscopy 25 (2):145-152.

2. Boughanem J, Riaz R, Patel RM, Sarwark JF (2011) Functional and Radiographic Outcomes of Juvenile Osteochondritis Dissecans of the Knee Treated With Extra-Articular Retrograde Drilling. Am J Sports Med 39 (10):2212-2217.

3. Conway FM (1937) Osteochondritis Dissecans. Description of the Stages of the Condition and Its Probable Traumatic Etiology. Am J Surg 38:691-699.

4. Crawford DC, Safran MR (2006) Osteochondritis dissecans of the knee. J Am Acad Orthop Surg 14 (2):90-100.

5. Detterline AJ, Goldstein JL, Rue JP, Bach BR, Jr. (2008) Evaluation and treatment of osteochondritis dissecans lesions of the knee. J Knee Surg 21 (2):106-115.

6. Fairbank HA (1933) Osteo-chondritis dissecans. Br Journal Surg 21 (81):67-82.

7. Flynn JM, Kocher MS, Ganley TJ (2004) Osteochondritis dissecans of the knee. J Pediatr Orthop 24 (4):434-443.

8. Geeslin AG, LaPrade RF (2010) Location of bone bruises and other osseous injuries associated with acute grade III isolated and combined posterolateral knee injuries. Am J Sports Med 38 (12):2502-2508.

9. Green JP (1966) Osteochondritis dissecans of the knee. J Bone Joint Surg Br 48 (1):82-91.

10. Hefti F, Beguiristain J, Krauspe R, Moller-Madsen B, Riccio V, Tschauner C, Wetzel R, Zeller R (1999) Osteochondritis dissecans: a multicenter study of the European Pediatric Orthopedic Society. J Pediatr Orthop B 8 (4):231-245.

11. Hughes JA, Cook JV, Churchill MA, Warren ME (2003) Juvenile osteochondritis dissecans: a 5-year review of the natural history using clinical and MRI evaluation. Pediatr Radiol 33 (6):410-417.

12. Kocher MS, Tucker R, Ganley TJ, Flynn JM (2006) Management of osteochondritis dissecans of the knee: current concepts review. Am J Sports Med 34 (7):1181-1191.

13. Krappel F, E B, U H (2005) Are bone bruises a possible cause of osteochondritis dissecans of the capitellum? A case report and review of the literature. Arch Orthop Trauma Surg 125 (8):545-549.

14. Miller MD, Osborne JR, Gordon WT, Hinkin DT, Brinker MR (1998) The natural history of bone bruises. A prospective study of magnetic resonance imaging-detected trabecular microfractures in patients with isolated medial collateral ligament injuries. Am J Sports Med 26 (1):15-19.

15. Paakkala A, Sillanpaa P, Huhtala H, Paakkala T, Maenpaa H (2010) Bone bruise in acute traumatic patellar dislocation: volumetric magnetic resonance imaging analysis with follow-up mean of 12 months. Skeletal Radiol 39 (7):675-682.

16. Sales de Gauzy J, Mansat C, Darodes PH, Cahuzac JP (1999) Natural course of osteochondritis dissecans in children. J Pediatr Orthop B 8 (1):26-28.

17. Shea KG, Grimm NL, Laor T, Wall E (2011) Bone bruises and meniscal tears on MRI in skeletally immature children with tibial eminence fractures. J Pediatr Orthop 31 (2):150-152.

18. Tei K, Kubo S, Matsumoto T, Matsushita T, Matsumoto A, Kurosaka M, Kuroda R (2012) Combined osteochondral fracture of the posterolateral tibial plateau and Segond fracture with anterior cruciate ligament injury in a skeletally immature patient. Knee Surg Sports Traumatol Arthrosc 20 (2):252-255.

19. Uozumi H, Sugita T, Aizawa T, Takahashi A, Ohnuma M, Itoi E (2009) Histologic findings and possible causes of osteochondritis dissecans of the knee. Am J Sports Med 37 (10):2003-2008.

20. Viskontas DG, Giuffre BM, Duggal N, Graham D, Parker D, Coolican M (2008) Bone bruises associated with ACL rupture: correlation with injury mechanism. Am J Sports Med 36 (5):927-933.

21. Wagoner G, and Cohn, B. N. E. (1931) Osteochondritis dissecans. A Resume of the Theories of Etiology and the Consideration of Heredity as an Etiologic Factor. Arch Surg 23:1-24.

22. Wall EJ, Vourazeris J, Myer GD, Emery KH, Divine JG, Nick TG, Hewett TE (2008) The healing potential of stable juvenile osteochondritis dissecans knee lesions. J Bone Joint Surg Am 90 (12):2655-2664.

23. Yonetani Y, Nakamura N, Natsuume T, Shiozaki Y, Tanaka Y, Horibe S (2010) Histological evaluation of juvenile osteochondritis dissecans of the knee: a case series. Knee Surg Sports Traumatol Arthrosc 18 (6):723-730. 


\section{Figure Legends:}

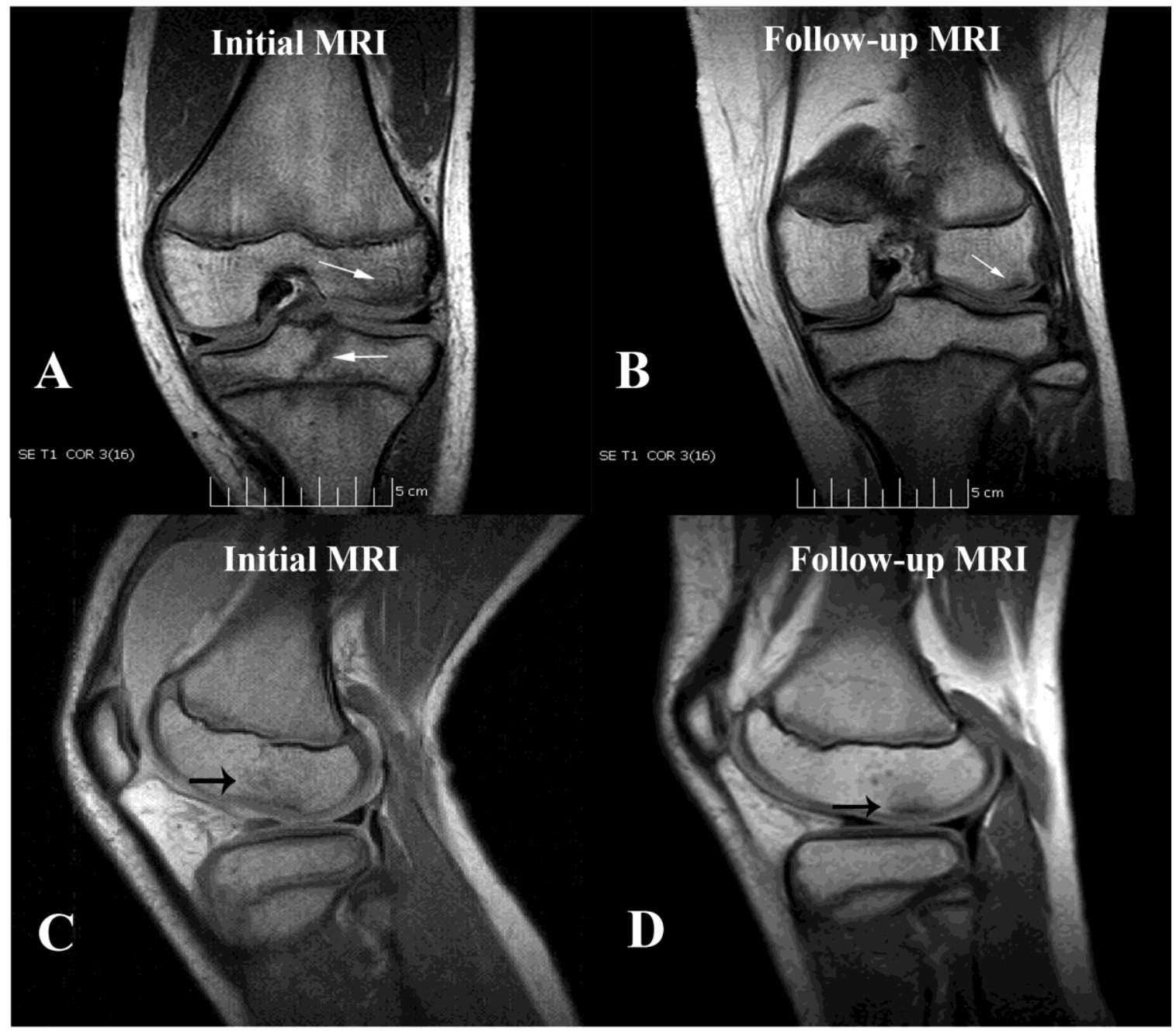

Figure 1. Case 1: A and C-Initial MRI showing lateral femoral condyle bone contusion (upper arrow) and tibial spine fracture (lower arrow); B and D-Follow-up MRI showing OCD lesion on lateral femoral condyle 2 years post tibial spine fracture. 


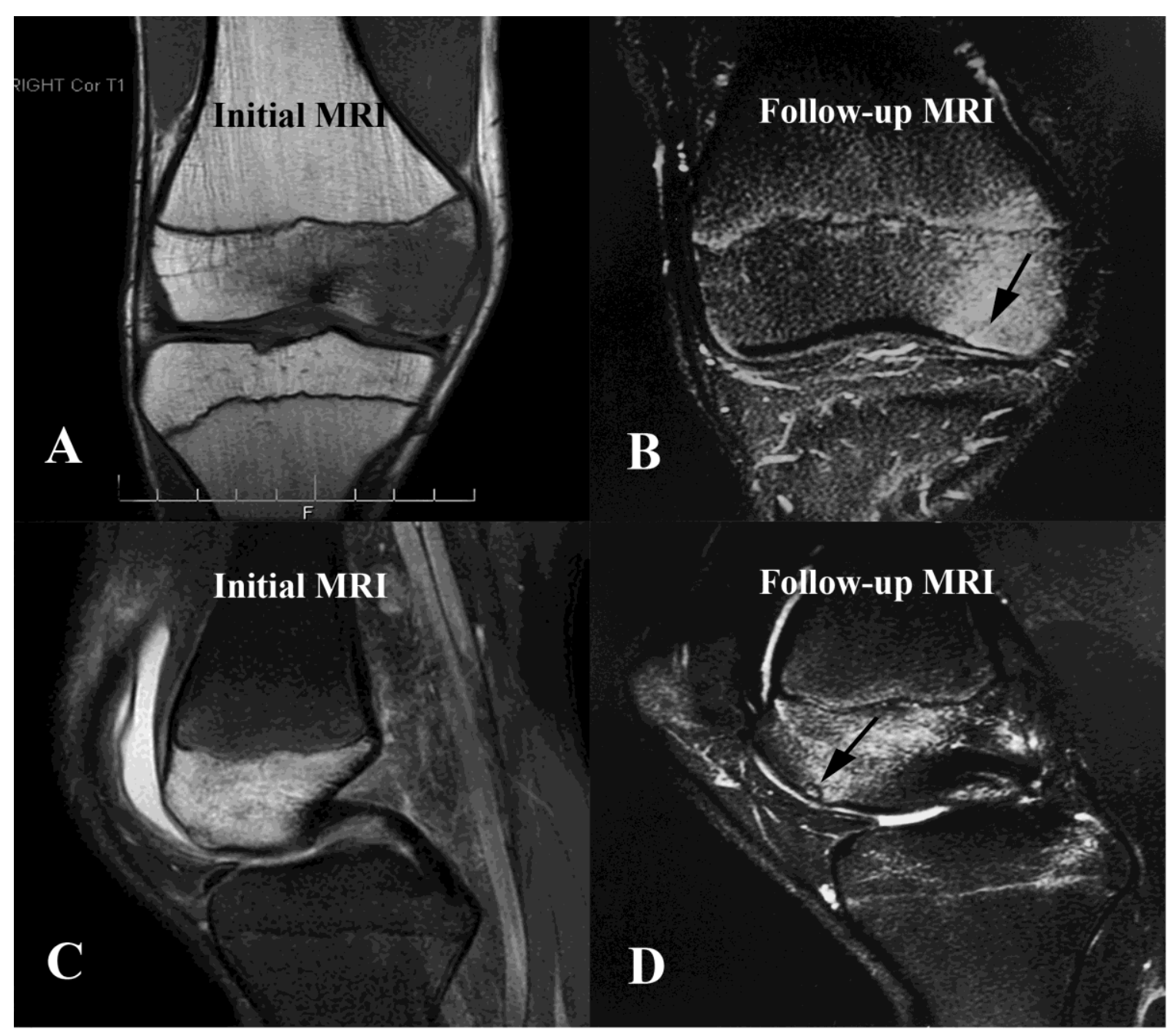

Figure 2. Case 2: A and C-Initial MRI showing medial femoral condyle bone contusion; B and D-Follow-up MRI showing OCD lesion (arrow) on medial femoral condyle 7 months post medial femoral condyle bone contusion. 